\title{
Effects of Low-Frequency Electromagnetic Fields on Chondrocytes in Short-Term Cultures
}

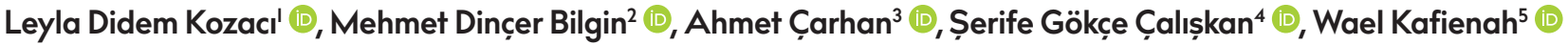 \\ 'Department of Medical Biochemistry, Ankara Yıldırım Beyazıt University School of Medicine, Ankara, Turkey \\ ${ }^{2}$ Department of Biophysics, Adnan Menderes University School of Medicine, Aydın, Turkey \\ ${ }^{3}$ Department of Medical Biology, Ankara Yıldırım Beyazıt University School of Medicine, Ankara, Turkey \\ ${ }^{4}$ Department of Physics, Adnan Menderes University Faculty of Science and Art, Aydın, Turkey \\ ${ }^{5}$ University of Bristol, School of Cellular and Molecular Medicine, Bristol, UK
}

ORCID IDs of the authors: L.D.K. 0000-000I-5422-I640; M.D.B. 0000-0003-0754-0854; A.C. 0000-0003-I584-0072; S.G.C̣. 0000-000I542I-3472; W.K. 0000-0003-I487-6823.

Cite this article as: Kozacı LD, Bilgin MD, Çarhan A, Çalıșkan ȘG, Kefienah W. Effects of Low-Frequency Electromagnetic Fields on Chondrocytes in Short-Term Cultures. Cyprus J Med Sci 2019; 4(3): 20I-7.

\section{BACKGROUND/AIMS}

Tissue engineering approaches have provided treatment options for patients with limited cartilage repair capacity. Most of these approaches rely on isolating and expanding chondrocytes in vitro. Mechanical stress, ultrasound, and electric and electromagnetic fields (EMFs) can be used to stimulate cartilage repair. EMF has been used in the management of conditions such as arthritis and fractures. Most of the previous studies have focused on low-frequency pulsed EMF (PEMF). The aim of the present study was to investigate the effects of low-frequency continuous (sinusoidal) EMF (CEMF) versus PEMF on chondrocytes.

\section{MATERIAL and METHODS}

Chondrocyłes from bovine nasal cartilage were exposed to low-frequency CEMF versus PEMF, and the proliferation and differentiation capacities of these chondrocytes were determined. The effects of EMFs on retinoic acid receptor beta and transforming growth factor beta (TGF- $\beta$ ) expressions were investigated using quantitative reverse transcription polymerase chain reaction.

RESULTS

Our observations suggested that there was no difference between the effects of PEMF and CEMF exposure on the proliferation and differentiation capacities of chondrocytes.

\section{CONCLUSION}

EMF-mediated proliferation of chondrocytes requires the presence of growth factors, especially insulin-like growth factor, in the environment to maintain the chondrogenic phenotype; furthermore, the EMF effect on chondrocytes is independent of TGF- $\beta$.

Keywords: Chondrocyte, electromagnetic field, growth factor, retinoic acid receptor

\section{INTRODUCTION}

Mechanical stress, ultrasound, and electric and electromagnetic fields (EMFs) can be used to stimulate cartilage repair by increasing cell proliferation and matrix synthesis. In the last few decades, numerous in vitro and in vivo studies have been conducted on pulsed EMF (PEMF) applied to cells from different species (I-3). Variable responses of chondrocytes to PEMF have been reported, as the studies have used diverse techniques $(4,5)$. However, the biological effects of PEMF and the underlying mechanisms of these effects are ill-defined. Because most of the exposure of humans in the natural environment is to low frequencies $(20-120 \mathrm{~Hz}$ ) of continuous (sinusoidal) EMF (CEMF), a study that investigates the effects of CEMF and PEMF on human cells is required. To our knowledge, there are few studies comparing the effects of different types of EMF (CEMF vs. PEMF).

Articular cartilage is composed of chondrocytes embedded in an extracellular matrix (ECM) of principally type II collagen and proteoglycan aggrecan molecules. On the other hand, collagen type I is often considered an indicator of fibrocartilage and dedifferentiation of chondrocytes to fibroblast-like cells (6). Chondrocytes can easily proliferate and produce ECM in a growth factor-supplemented medium. Several growth factors such as fibroblast growth factor-2 (FGF-2), insulin-like 
growth factor I (IGF-I), transforming growth factor beta (TGF- $\beta$ ), and retinoic acid (RA) have been shown to be essential for the expansion of chondrocytes and the maintenance of their chondrogenic capacity (7-9). Endogenously produced growth factors, such as TGF- $\beta$ and IGF-I, increase cartilage-specific gene expression in chondrocytes $(7,8)$. FGF-2 has been shown to enhance the proliferative and redifferentiation capacity of mature chondrocytes and the chondrogenic capacity of human mesenchymal stem cells (IO, II). RA, an active vitamin A metabolite, acts through its receptors (retinoic acid receptors, RARs). RARs act as ligand-activated transcription factors and participate in the growth and differentiation of several tissues including cartilage (2_ENREF_5, 12-14). RA and TGF- $\beta$ signaling have been shown to interact during chondrogenesis in several systems $(12,14)$. Kafienah et al. (I5) have highlighted the importance of these receptors in chondrogenesis by using antagonists against the receptors. $\mathrm{Li}$ et al. (16) have reported a decrease in TGF- $\beta$ protein levels with the addition of a retinoic acid receptor beta (RAR $\beta$ ) inhibitor, suggesting a synergistic interaction between TGF- $\beta$ and RA in chondrogenesis. However, limited data are available on the interaction of other growth factors with RA receptors.

In the present study, the effects of low-frequency CEMF versus PEMF on chondrocyte proliferation and differentiation capacities in vitro were investigated and the question whether the effects of EMFs occur through RAR $\beta$ and TGF- $\beta$ or not was asked.

\section{MATERIALS and METHODS}

\section{Isolation of Chondrocytes from Cartilage}

Full-thickness bovine nasal cartilage obtained from a local abattoir was harvested aseptically from adult animals ( $n=5$; age, $16-20$ months). Ethics committee approval was received for this study from the Adnan Menderes University Animal Ethics Committee (Approval Date: 24.06.2005, Approval Number: 010-017) and the abattoir gave permission for the use of cartilage tissue. Freshly dissected cartilage from individual animals was cut into slices of $5 \mathrm{~cm} \times 1.5 \mathrm{~cm} \times 2 \mathrm{~mm}$ using a scalpel. The slices were washed once with sterile phosphate-buffered saline (Sigma, Darmstadt, Germany) for $20 \mathrm{~min}$. Chondrocytes were isolated from the cartilage through sequential digestion at $37^{\circ} \mathrm{C}$ for $15 \mathrm{~min}$ with $\mathrm{Img} / \mathrm{mL}$ of testicular hyaluronidase (Sigma), 0.25\% w/v trypsin (Sigma) for $30 \mathrm{~min}$, and $1.5 \mathrm{mg} / \mathrm{mL}$ of clostridial collagenase (Sigma) in an expansion medium comprising Dulbecco's Modified Eagle's Medium (DMEM; Sigma) containing 10\% ( $/ \mathrm{v}$ ) fetal calf serum overnight on an orbital shaker. Isolated chondrocytes were centrifuged and resuspended in an expansion medium containing $100 \mathrm{U} / \mathrm{mL}$ penicillin and $100 \mu \mathrm{g} / \mathrm{mL}$ streptomycin (Sigma). Cells were counted using a hemocytometer, plated in 24-well plates (Nunc, Denmark) in monolayer $\left(\mid \times 10^{5}\right.$ cells $\left./ \mathrm{cm}^{2}\right)$, and cultured to equilibrate for $48 \mathrm{~h}$ at $37^{\circ} \mathrm{C}$ in a humidified atmosphere of $5 \% \mathrm{CO}_{2} / 95 \%$ air.

\section{Culture of Chondrocytes and Exposure to EMF}

Chondrocytes were cultured to reach confluence for $48 \mathrm{~h}$ and then exposed to EMF and growth factors for 7 days. During EMF treatment experiments, cells were cultured with DMEM, $100 \mathrm{U} / \mathrm{mL}$ penicillin, $100 \mu \mathrm{g} / \mathrm{mL}$ streptomycin, and $2 \mathrm{mM}$ glutamine without fetal bovine serum. Growth factors were added as $10 \mathrm{ng} / \mathrm{mL}$ IGF (Sig$\mathrm{ma}$ ) and $50 \mathrm{ng} / \mathrm{mL}$ FGF-2 (Sigma). Growth factor concentrations used in the study were determined as described in the literature (17). Cells were exposed to either CEMF or PEMF in the absence or presence of growth factors for $30 \mathrm{~min} /$ day for 7 days at room temperature and then replaced back into the incubator. Non-EMF exposed cells were also treated the same way, except EMF application. Before EMF application, optimal EMF dose that can drive maximum cell proliferation was determined by searching the literature $(3,18,19)$. It is difficult to characterize the specific beneficial EMF dose due to the broad range of intensity reported in the literature and the external condition effects. EMFs ranging from I to $3 \mathrm{mT}$ appear to generate positive results on the cartilage.

During cell cultures, chondrocytes were exposed to CEMF or PEMF in the north-south direction. Three study groups were defined: (I) CEMF group, (2) PEMF group, and (3) control group. Chondrocytes cultured in the absence of growth factors and EMF were used as the negative control group. The control group was maintained at identical conditions, except for CEMF or PEMF exposure. The reason for applying $30 \mathrm{~min}$ exposure to EMF was to determine whether a short-term treatment with the growth factors has transient or persistent influence on chondrocytes. Figures la and $b$ show the CEMF and PEMF exposure setup, respectively. After 7 days in culture, the pro-

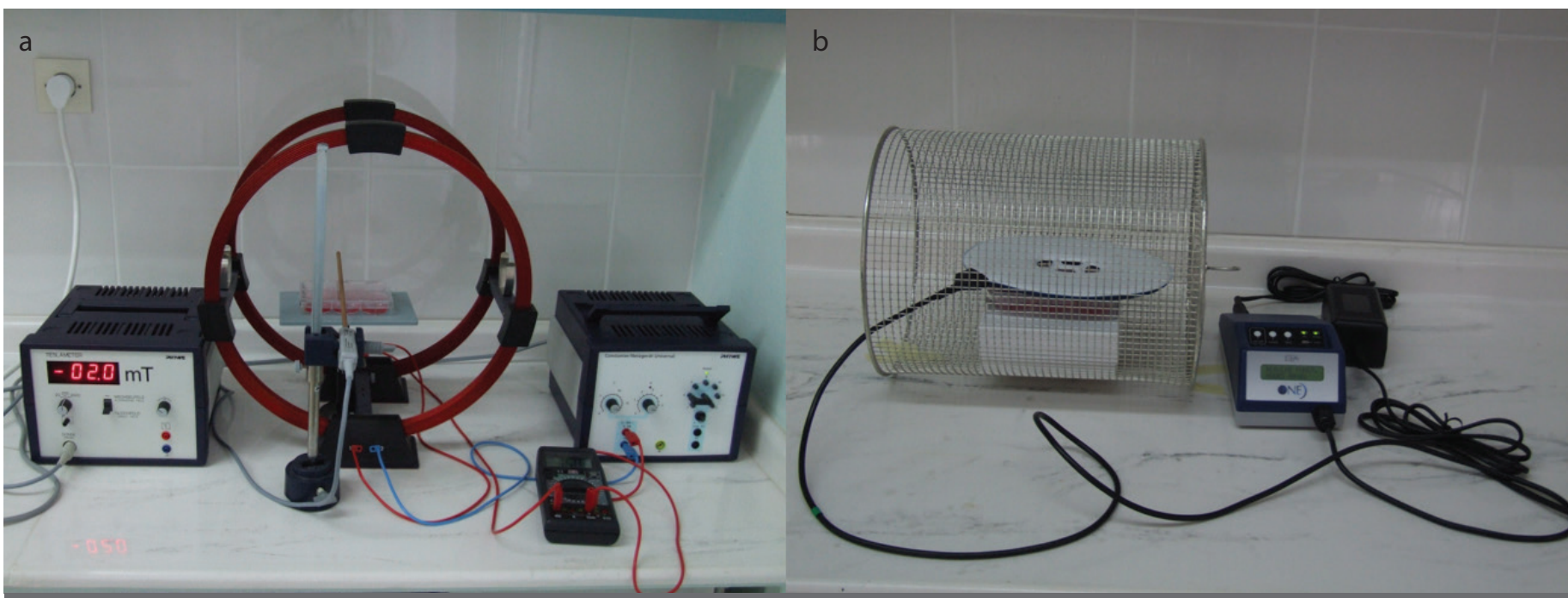

Figure I. a, b. Photographs of CEMF (a) and PEMF (b) bioreactors and the experimental design used in our study. Chondrocytes were exposed to $2 \mathrm{mT}$ and $50 \mathrm{~Hz}$ (30 min/day) for CEMF exposure (a) and $75 \mathrm{~Hz}$ and $2.3 \mathrm{mT}$ ( $30 \mathrm{~min} /$ day) for PEMF exposure for 7 days CEMF: continuous electromagnetic field; PEMF: pulsed electromagnetic field 
liferation capacity of cells was determined by counting them using a hemocytometer. Cell samples were also collected and stored in RNAlater solution (Ambion; Thermo Fisher Scientific, Inc, Waltham, MA, USA) accordingly for further molecular analyses.

\section{CEMF Exposure Conditions}

Cultures were exposed to $50 \mathrm{~Hz}$ CEMFs in the north-south direction. CEMF was generated by a pair of Helmholtz coils, each having 154 turns and carrying a maximum of $5 \mathrm{~A}$, with a resistance of $2.1 \Omega$. The coils were separated by a distance of $40 \mathrm{~cm}$, equal to the radius of the coil, with a maximum flux density for I=5 A in a Helmholtz array of $3.5 \mathrm{mT}$ (Phywe, Germany). Chondrocytes were exposed to $50 \mathrm{~Hz}$ and $2 \mathrm{mT}$ EMF (30 min/day) for 7 days. Intensities of CEMF between the two circular coils were monitored during the experiments using a digital gaussmeter/ teslameter (Model 7030, F.W. Bell, Syprus, Orlando, FL, USA). Multiwell plates were placed in the mid-plane between the two coils at a point where theoretical calculations showed a uniform magnetic field (Figure la).

\section{PEMF Exposure Conditions}

Pulsed EMF exposure apparatus consisted of a pair of Helmholtz coils placed opposite to each other and in a signal generator (IGEA, Carpi, Italy) (Figure lb). Multiwell plates were placed between Helmholtz coils so that the plane of the coils was perpendicular to the plates. The pulsed signal parameters were as follows: pulse duration, I.3 ms; magnetic field intensity, $2.3 \mathrm{mT}$; induced electric field, $2 \mathrm{mV}$; frequency, $75 \mathrm{~Hz}$; and yielding duty of cycle, I/I0. Chondrocytes were exposed to PEMF (30 min/day) for 7 days. Intensities of magnetic fields were measured using a digital gaussmeter/teslameter (Model 7030, F.W. BELL, Syprus). The magnetic field was uniform and focused on the plates placed between the two coils.

\section{RNA Isolation and Reverse Transcription}

Total RNA was prepared from chondrocytes (obtained from 5 animals, each analyzed individually) using the RNeasy Mini Kit (Qiagen, Hilden, Germany). RNA quality at $\mathrm{OD}_{260 / 280}$ of the samples was checked using Qubit fluorometer (Thermo Fisher Scientific). Quantitative reverse transcription polymerase chain reaction ( $q R T-P C R$ ) was used to quantify mRNA levels for collagen type I (dedifferentiation marker), collagen II and aggrecan (chondrogenic markers), and TGF- $\beta$ and RAR $\beta$ in cultured chondrocytes (13, 15). Briefly, cDNA was generated using reverse transcriptase (Promega, UK). PCRs were performed using SYBR ${ }^{\circledR}$ Premix Ex Taq ${ }^{\text {TM }}$ (Takara, Gennevilliers, France) and monitored using Rotor-Gene 6000 Real-Time PCR system. Primer sequences for TGF- $\beta$ were as follows: forward 5'-CTGCTGAGGCTCAAGTTAAAAGTG-3' and reverse 5'-CAGCCGGTTGCTGAGGTAG-3'. The cycle conditions for $P C R$ and sequences of the primers for type I and II collagens, aggrecan, and RAR $\beta$ were as previously described $(13,15)$. The expression levels for the genes of interest were normalized to $\beta$-actin.

\section{Statistical Analysis}

Statistical analyses were performed using analysis of variance. Data were expressed as mean \pm SEM. A $p$ value of $<0.05$ was considered as statistically significant.

\section{RESULTS}

Effects of EMF Exposure and/or Growth Factors on Chondrocyte Proliferation Rate

The effects of EMF exposure and growth factor treatment on chondrocyte proliferation are summarized in Figure 2. On day 0 , equal numbers of cells were placed in wells $\left(5 \times 10^{5} /\right.$ well). In the control group, an increase $(\times 2.6)$ in the chondrocyte number was observed in the absence of EMF or growth factors on day 7. Applied on its own, EMF's effect on cell proliferation was negligible compared with that in the control group. Both growth factors, especially FGF-2 ( $p=0.038)$, stimulated chondrocyte proliferation significantly. Additionally, IGF and FGF-2 led to a 4-6 times increase in the cell number. The combination of EMF (whether continuous or pulsating) and growth factors led to a significant increase in the proliferation rate of the cells (Figure 2). This effect was most pronounced in the presence of FGF-2 ( $p=0.005)$.

\section{Effects of EMF Exposure and/or Growth Factors on the Synthe- sis of Cartilage Proteins}

The effects of EMF exposure and/or growth factor treatment on cartilage protein syntheses are summarized in Figure 3. mRNAs were isolated from the chondrocytes cultured in monolayers for 7 days and analyzed using qRT-PCR for collagens type I (Figure $3 a$ ) and type II (Figure 3b) and aggrecan (Figure 3c). Type II collagen expression was lower in cells treated with IGF-I (I0 $\mathrm{ng} / \mathrm{mL}$ ) or FGF-2 (50 $\mathrm{ng} / \mathrm{ml}$ ) than in controls. Both PEMF and CEMF caused an increase in type I collagen expression. IGF-I reversed PEMF's stimulatory effects on type I collagen expression, whereas FGF-2 exerted effects similar to those of CEMF. Aggrecan expression was also differentially affected by PEMF in the presence or absence of the growth factors FGF-2 or IGF-I (Figure 3c).

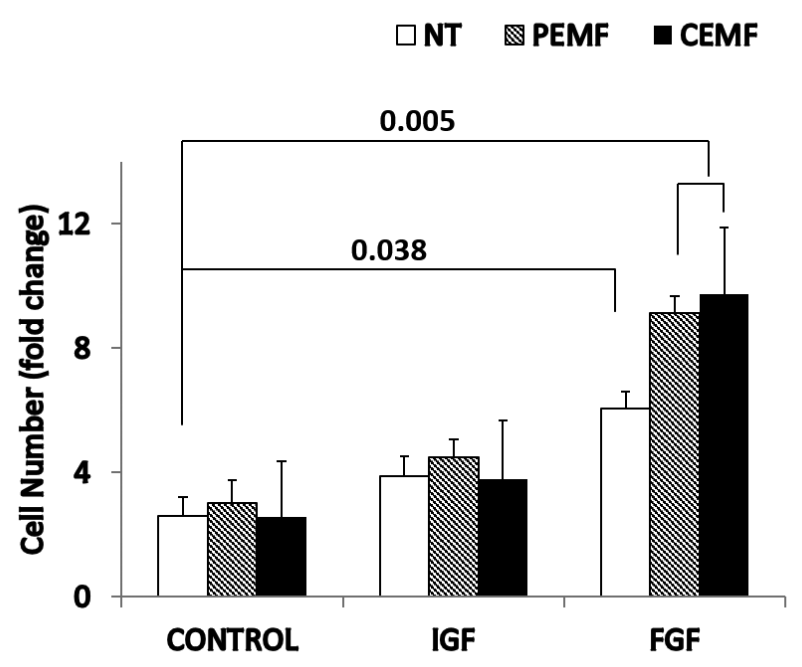

Figure 2. Effects of EMF and growth factors on chondrocyte proliferation in monolayer cell cultures. The fold change in cell number in each plate on day 7 was compared with the cell number seeded on plates on day 0 . Results are expressed as mean \pm SEM $(n=5)$. A p value of $<0.05$ was accepted as significant using ANOVA EMF: electromagnetic field; SEM: standart error of mean; NT: untreated; CEMF: continuous electromagnetic field; PEMF: pulsed electromagnetic field; 


\section{Effects of EMF and/or Growth Factors on TGF- $\beta$ and RAR $\beta$ Ex- pressions}

TGF- $\beta$ plays a critical role in chondrogenesis. Therefore, we questioned whether exposure to EMF induces a change in endogenous TGF- $\beta$ expression. IGF and FGF-2 have been reported to crosstalk with TGF- $\beta$ (20). CEMF and PEMF were applied in the absence or presence of IGF and FGF. As shown in Figure 4, a significant increase in TGF- $\beta$ expression was observed when growth factors were used in combination with EMF applications. Interestingly, the effects of EMF on TGF- $\beta$ expressions were growth factor and/or EMF type dependent. While the combination of CEMF with IGF-I has a maximum stimulatory effect on TGF- $\beta$ expression, this effect was reversed when CEMF was combined with FGF-2. On the other hand, the combination of FGF-2 with PEMF caused a significant increase in TGF- $\beta$ expression (Figure 4).

In cultures, RAR $\beta$ expression was differentially affected by growth factors and/or EMF exposures (Figure 5). RAR $\beta$ expression decreased when chondrocytes were treated with EMF, ap- plied alone. IGF-I also caused a decrease in RAR $\beta$ expression on its own. On the other hand, FGF-2 caused a significant increase in RAR $\beta$ expression, with the increase being most prominent in combination with PEMF (Figure 5).

\section{DISCUSSION}

Recent interest in the use of mechanical stimulation such as EMF application has made it necessary to understand how these agents regulate gene expression in connective tissue cells.

EMF is one of the most treated therapeutic alternatives on tissue repair. It exerts positive effects on tissue metabolism through hyperemization (2l). The piezoelectric structure of the ECM of hyaline cartilage allows the conversion of electromagnetic oscillations to mechanical vibrations and vice versa (22). Reportedly, EMF treatment improves suboptimal or degenerate cellular conditions in chondrocytes (23). Furthermore, we are constantly exposed to low-frequency CEMF at home as well as at work by technological processes. In clinical practice, due to their positive effects, EMFs are used in various instruments. a

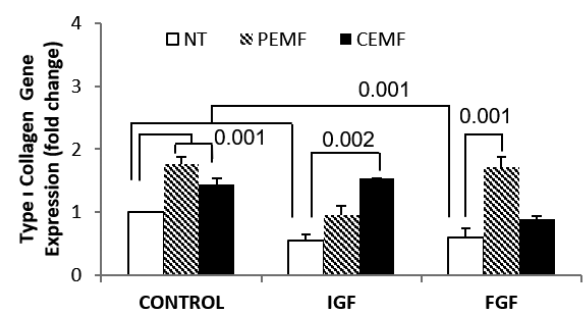

b

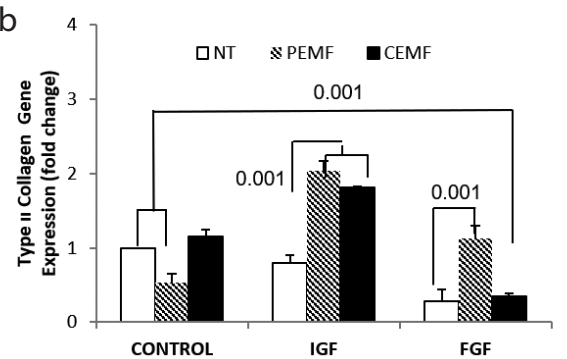

C

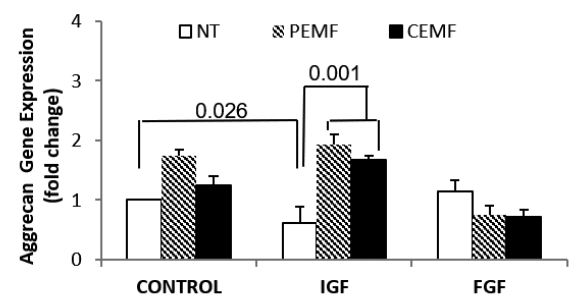

Figure 3. a-c. Quantitative mRNA analysis of cartilage matrix proteins in bovine nasal chondrocyte cultures. Chondrocytes in monolayer were incubated with/without $10 \mathrm{ng} / \mathrm{mL}$ IGF, $50 \mathrm{ng} / \mathrm{mL}$ FGF-2, and/or PEMF and CEMF for 7 days. Total RNA was harvested at the end of the culture period and analyzed using qRT-PCR for mRNA of type I collagen (a), type II collagen (b), and aggrecan (c). mRNA expression is shown as the relative change over untreated chondrocyte controls. Results are expressed as mean $\pm \operatorname{SEM}(n=5)$. A p value of $<0.05$ was accepted as significant using ANOVA. Detailed methodology has been presented in the materials and methods section

CEMF: continuous electromagnetic field; PEMF: pulsed electromagnetic field; SEM: standart error of mean; NT: untreated; IGF: insulin-like growth factor; FGF; fibroblast growth factor

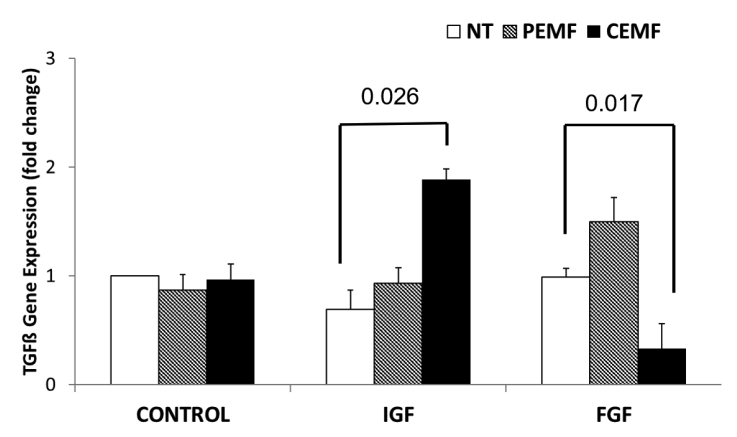

Figure 4. Quantitative mRNA analysis of TGF- $\beta$ in monolayer bovine nasal chondrocyte cultures. Chondrocytes in monolayer were incubated with/without $10 \mathrm{ng} / \mathrm{mL}$ IGF, $50 \mathrm{ng} / \mathrm{mL}$ FGF-2, and/or PEMF and CEMF for 7 days. Total RNA was harvested at the end of the culture period and analyzed using qRT-PCR for mRNA of TGF- $\beta$. mRNA expression is shown as the relative change over untreated chondrocyte controls. Results are expressed as mean $\pm \operatorname{SEM}(n=5)$. A $p$ value of $<0.05$ was accepted as significant using ANOVA. Detailed methodology has been presented in the materials and methods section

CEMF: continuous electromagnetic field; PEMF: pulsed electromagnetic field; NT: untreated; SEM: standart error of mean; IGF: insulin-like growth factor; FGF: fibroblast growth factor

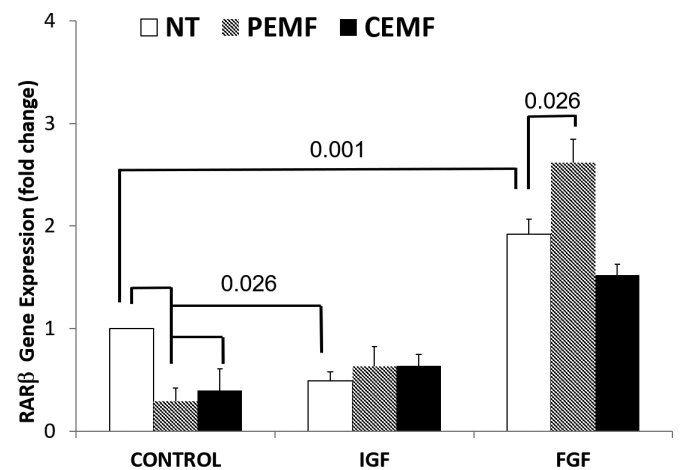

Figure 5. Quantitative mRNA analysis of RAR $\beta$ in monolayer bovine nasal chondrocyte cultures. Chondrocytes in monolayer were incubated with/without $10 \mathrm{ng} / \mathrm{mL}$ IGF, $50 \mathrm{ng} / \mathrm{mL}$ FGF-2, and/or PEMF and CEMF for 7 days. Total RNA was harvested at the end of the culture period and analyzed using qRT-PCR for mRNA of RAR $\beta$. mRNA expression is shown as the relative change over untreated chondrocyte controls. Results are expressed as mean \pm SEM $(n=5)$. A $p$ value of $<0.05$ was accepted as significant using ANOVA. Detailed methodology has been presented in the Materials and Methods section

CEMF: continuous electromagnetic field; PEMF: pulsed electromagnetic field; NT: untreated; IGF: insulin-like growth factor; FGF: fibroblast growth factor RARß: retinoic acid receptor beta 
In the present study, data on the effects of low-frequency CEMF and PEMF on bovine nasal cartilage chondrocytes in the absence or presence of either FGF-2 or IGF-I in short-term monolayer cultures were presented. CEMF was applied as $50 \mathrm{~Hz}$ and $2 \mathrm{mT}$ EMF, whereas for PEMF, pulse duration of the signal, repetition rate, and intensity of magnetic field were $1.3 \mathrm{~ms}, 75 \mathrm{~Hz}$, and $2.3 \mathrm{mT}$, respectively. Both FGF-2 and IGF-I are commonly used in tissue engineering techniques to maintain chondrogenic differentiation.

In the present study, first, the proliferation capacity of chondrocytes was monitored. Nasal chondrocytes isolated from the nasal septum have been reported to be a promising alternative cell source for cartilage tissue engineering (24). Their ECM components are similar to those of articular chondrocytes (25). Furthermore, they have been shown to respond to biomechanical stimulation like articular chondrocytes (26). Our results showed that EMF alone did not increase the proliferation capacity of chondrocytes in monolayer chondrocyte cultures. Previous studies have reported that $50 \mathrm{~Hz}$ EMF can enhance cell proliferation of various cell types, such as human epidermal stem cells and keratinocytes in vitro $(27,28)$. However, our findings are in agreement with those of Schmidt-Rohlfing et al. (I) who reported that 14 days of exposure to $50 \mathrm{~Hz}$ CEMF with a flux density up to $2 \mathrm{mT}$ has no effect on human adult osteoarthritic chondrocytes. Interestingly, in our study, EMF intensified the proliferative effects of growth factors (IGF-I and FGF-2) on bovine nasal chondrocytes. EMF effect with FGF-2 was more potent than that with IGF-I (Figure 2). Thus far, we cannot say whether this effect observed with FGF-2 and EMF was an additive or a synergistic effect. On the other hand, Vincent et al. (29) have shown that PEMF increases endogenous FGF-2 release from endothelial cells in diabetic mice. This suggests a synergistic effect for EMF. Another explanation for the improved FGF-2 effect may be the induction of its receptor by EMF. Such an effect has been reported by Fitzsimmons et al. (30) showing that combined magnetic fields induce the release of IGF-II and IGF-II receptors in human osteosarcoma cell line (TE85).

Second, the effects of EMFs on mRNA expressions of type I and II collagens and aggrecan in the presence or absence of growth factors (IGF-I and FGF-2) were examined. Both growth factors have been reported to influence matrix production and deposition in cartilage. IGF-I reportedly promotes proteoglycan production in a dose-dependent manner (3I). FGF-2 has been shown to increase not only the proliferation capacity of bovine articular chondrocytes but also the synthesis of glycosaminoglycans (20). We observed a decrease in type I and II collagen expressions with FGF-2 treatment, whereas no change was observed in aggrecan expression (Figure 3). There was no major difference in type I and II collagen expression levels between chondrocytes exposed to PEMF and CEMF alone. However, EMF in combination with growth factors (FGF-2 and IGF-I) caused changes in the collagen production in bovine nasal chondrocytes. PEMF in combination with FGF-2 reversed the inhibitory effects of the growth factor on collagen synthesis and slightly increased type II collagen expression (Figure 3a, b). Furthermore, PEMF intensified the stimulatory effects of IGF-I on aggrecan synthesis. However, it significantly inhibited aggrecan expression in combination with FGF-2 (Figure 3c). The stimulatory effect of combined PEMF and IGF-I applications on aggre- can synthesis observed in this study is in agreement with the results of previous studies $(2,32)$. Our findings regarding combined FGF-2 and EMF applications are in agreement with those of Chang et al. (4) who suggested that chondrocytes somehow terminate the synthesis and deposition of ECM proteins while proliferating.

The EMF effect on RAR $\beta$ and TGF- $\beta$ expressions was further explored. RARs have been shown to act as transcription factors and play important roles in chondrogenesis by several groups $(12,13,16)$. Kafienah et al. (15) have highlighted the importance of these receptors in chondrogenesis using antagonists against these receptors. They have reported that RA receptors are expressed differentially during chondrocyte maturation and that RAR $\beta$ is downregulated during chondrogenesis induced by TGF- $\beta$ (I3). Furthermore, they have reported that RAR $\beta$ expression is negatively correlated with COL2, aggrecan, and SOX9 productions in TGF- $\beta$-treated 3D chondrocyte cultures (I3). On the other hand, Diederich et al. (12) have reported that RAR $\beta$ expression is induced by TGF- $\beta$ in human chondrogenic stem cell pellet cultures, suggesting RAR $\beta$ to be a good target in studies related to chondrogenesis. However, Zhang et al. (14) have explored the interactions of RA and TGF- $\beta$ signaling during chondrogenesis and reported a negative functional interplay between RA and TGF- $\beta$ during chondrogenesis in mouse embryonic palate mesenchymal cells, which in agreement with the findings of Kafienah et al. (15). These discrepancies in the effects of TGF- $\beta$ on RAR $\beta$ expressions reported by different research groups are possibly related to the chosen culture conditions, namely $2 \mathrm{D}$ (monolayer) or 3D (pellet- or scaffold-based) systems. To test whether EMF has any effect on RAR $\beta$ and TGF- $\beta$ expressions, the mRNA levels of RAR $\beta$ and TGF- $\beta$ in our culture conditions were measured. We hypothesized that RAR $\beta$ expression need not be changed or downregulated if the chondrocytes maintain their chondrogenic phenotype with EMF treatment. Both CEMF and PEMF treatments alone or in combination with IGF, but not with FGF-2, downregulated RAR $\beta$ expression in chondrocytes. CEMF upregulated RAR $\beta$ expression in combination with FGF-2 (Figure 4). No significant changes were observed in TGF- $\beta$ expression levels in comparison with the controls. In cell cultures where RAR $\beta$ expression was upregulated, in agreement with the findings of Kafienah et al. (15), down-regulation was observed in type II collagen and aggrecan expression levels of chondrocytes (Figure $3 b, c$ ). Both PEMF and CEMF alone downregulated RAR $\beta$ expression and caused a slight increase in type II collagen expression (Figure 3b). In our study, induced chondrocyte proliferation with combined EMF and FGF-2 application and increased RAR $\beta$ expression may be due to the dedifferentiation of rapidly proliferating chondrocytes. RAR $\alpha$ expression was not affected by any treatment (data not shown).

Only few studies in the literature have discussed the effects of both PEMF and CEMF on various cells $(21,33)$. Stolfa et al. (2l) have reported that a static magnetic field is more appropriate than PEMF for the stimulation of the metabolic activity of chondrocytes, but in our study, we did not find any difference between the effects of CEMF and PEMF exposure to chondrocytes. Furthermore, it has been suggested that CEMF exposure may induce adaptive mechanisms in cells, protecting the genome from harmful influences, whereas PEMF exposure results in the formation of DNA breaks (34). However, another study has shown completely 
diverse effects (35). These differences may be directly related to the methodologies, exposure time, frequency, magnetic field intensity, and cell type used in the studies.

Our study has few limitations. Instead of using 3D cultures (pellet- or scaffold-based), we used monolayer primary chondrocytes that may limit the adaptation and evaluation of the effects of PEMF and CEMF in vitro systems with 3D environments. We aimed to overcome this limitation by culturing primary bovine nasal chondrocytes only up to 7 days and analyzing growth factor and matrix protein expressions at this time point.

To our knowledge, this is the first study to analyze CEMF effects on chondrocytes in the presence or absence of growth factors (IGF-I and FGF-2) by means of ECM protein (TGF- $\beta$ and RAR $\beta$ ) expression. Data reported in the present study, together with previous reports, suggest that EMF exposure may be of interest in cartilage tissue engineering due to its ability to stimulate chondrocyte proliferation and differentiation. Our observations suggest that EMF-mediated chondrocyte proliferation requires the presence of growth factors, especially IGF, in the environment to maintain the chondrogenic phenotype and that EMF effects on chondrocytes are independent of TGF- $\beta$ and there is no correlation between TGF- $\beta$ and RAR $\beta$ expressions.

Ethics Committee Approval: Ethics committee approval was received for this study from Adnan Menderes University Animal Ethics Committee (Approval Date: 24.06.2005, Approval Number: 010-017).

\section{Informed Consent: N/A.}

Peer-review: Externally peer-reviewed.

Author contributions: Concept - L.D.K., M.D.B.; Design - L.D.K., M.D.B.; Supervision - L.D.K., M.D.B.; Resource - L.D.K., M.D.B.; Materials - L.D.K., M.D.B., W.K.; Data Collection and/or Processing - L.D.K., M.D.B., A.C.; Analysis and/or Interpretation - L.D.K., S..G.C., A.C.; Literature Search L.D.K., M.D.B., A.C., S.G.C..; Writing - L.D.K., M.D.B., A.C.., W.K.; Critical Reviews - L.D.K., M.D.B., A.C., W.K.

Conflict of Interest: The authors have no conflicts of interest to declare.

Financial Disclosure: Part of this project was supported by The Scientific and Technological Research Council of Turkey; Grant Number: I04S434.

\section{REFERENCES}

I. Schmidt-Rohlfing B, Silny J, Woodruff S, Gavenis K. Effects of pulsed and sinusoid electromagnetic fields on human chondrocytes cultivated in a collagen matrix. Rheumatol Int 2008; 28(I0): 97I-7. [CrossRef]

2. Ongaro A, Pellati A, Masieri FF, Caruso A, Setti S, Cadossi R, et al. Chondroprotective effects of pulsed electromagnetic fields on human cartilage explants. Bioelectromagnetics 20II; 32(7): 543-5I. [CrossRef]

3. Veronesi F, Torricelli P, Giavaresi G, Sartori M, Cavani F, Setti S, et al. In vivo effect of two different pulsed electromagnetic field frequencies on osteoarthritis. J Orthop Res 2014; 32(5): 677-85. [CrossRef]

4. Chang $\mathrm{CH}$, Loo ST, Liu HL, Fang HW, Lin HY. Can low frequency electromagnetic field help cartilage tissue engineering? J Biomed Mater Res A 2010; 92(3): 843-51.

5. Ciombor DM, Aaron RK, Wang S, Simon B. Modification of osteoarthritis by pulsed electromagnetic field--a morphological study. Osteoarthritis Cartilage 2003; II(6): 455-62. [CrossRef]

6. Poole AR, Kojima T, Yasuda T, Mwale F, Kobayashi M, Laverty S. Composition and structure of articular cartilage: a template for tissue repair. Clin Orthop Relat Res 200I: S26-33. [CrossRef]
7. Xu C, Oyajobi BO, Frazer A, Kozaci LD, Russell RG, Hollander AP. Effects of growth factors and interleukin-I alpha on proteoglycan and type II collagen turnover in bovine nasal and articular chondrocyte pellet cultures. Endocrinology 1996; 137(8): 3557-65. [CrossRef]

8. Lisignoli G, Cristino S, Piacentini A, Toneguzzi S, Grassi F, Cavallo C, et al. Cellular and molecular events during chondrogenesis of human mesenchymal stromal cells grown in a three-dimensional hyaluronan based scaffold. Biomaterials 2005; 26(28): 5677-86. [CrossRef]

9. Yang KG, Saris DB, Geuze RE, Helm YJ, Rijen MH, Verbout AJ, et al. Impact of expansion and redifferentiation conditions on chondrogenic capacity of cultured chondrocytes. Tissue Eng 2006; 12(9): 2435-47. [CrossRef]

10. Kafienah W, Jakob M, Demarteau O, Frazer A, Barker MD, Martin I, et al. Three-dimensional tissue engineering of hyaline cartilage: Comparison of adult nasal and articular chondrocytes. Tissue Eng 2002; 8(5): 817-26. [CrossRef]

II. Solchaga LA, Penick K, Goldberg VM, Caplan Al, Welter JF. Fibroblast growth factor-2 enhances proliferation and delays loss of chondrogenic potential in human adult bone-marrow-derived mesenchymal stem cells. Tissue Eng Part A 2010; 16(3): 1009-19. [CrossRef]

12. Diederichs S, Zachert K, Raiss P, Richter W. Regulating chondrogenesis of human mesenchymal stromal cells with a retinoic Acid receptor-Beta inhibitor: differential sensitivity of chondral versus osteochondral development. Cell Physiol Biochem 20l4; 33(6): 1607-19. [CrossRef]

13. Kafienah W, Mistry S, Dickinson SC, Sims TJ, Learmonth I, Hollander AP. Three-dimensional cartilage tissue engineering using adult stem cells from osteoarthritis patients. Arthritis Rheumatol 2007; 56(I): 177-87. [CrossRef]

14. Zhang H, Li N, Tang Y, Wu W, Zhang Q, Yu Z. Negative functional interaction of retinoic acid and TGF-beta signaling mediated by TG-interacting factor during chondrogenesis. Cell Physiol Biochem 2009; 23(I-3): 157-64. [CrossRef]

15. Kafienah W, Mistry S, Perry MJ, Politopoulou G, Hollander AP. Pharmacological regulation of adult stem cells: Chondrogenesis can be induced using a synthetic inhibitor of the retinoic acid receptor. Stem Cells 2007; 25(I0): 2460-8. [CrossRef]

16. LiZ, Yao SJ, Alini M, StoddartMJ. The role of retinoic acid receptor inhibitor LEI35 on the osteochondral differentiation of human bone marrow mesenchymal stem cells. J Cell Biochem 20ll; II2(3): 963-70. [CrossRef]

17. Shi S, Mercer S, Eckert GJ, Trippel SB. Growth factor regulation of growth factors in articular chondrocytes. J Biol Chem 2009; 284(II): 6697-704. [CrossRef]

18. De Mattei M, Fini M, Setti S, Ongaro A, Gemmati D, Stabellini G, et al. Proteoglycan synthesis in bovine articular cartilage explants exposed to different low-frequency low-energy pulsed electromagnetic fields. Osteoarthritis Cartilage 2007; 15(2): 163-8. [CrossRef]

19. Pezzetti F, De Mattei M, Caruso A, Cadossi R, Zucchini P, Carinci F, et al. Effects of pulsed electromagnetic fields on human chondrocytes: An in vitro study. Calcif Tissue Int 1999; 65(5): 396-40I. [CrossRef]

20. Pei M, Seidel J, Vunjak-Novakovic G, Freed LE. Growth factors for sequential cellular de- and re-differentiation in tissue engineering. Biochem Biophys Res Commun 2002; 294(I): 149-54. [CrossRef]

21. Stolfa S, Skorvanek M, Stolfa P, Rosocha J, Vasko G, Sabo J. Effects of static magnetic field and pulsed electromagnetic field on viability of human chondrocytes in vitro. Physiol Res 2007; 56(Suppl I): S45-9.

22. Gal P, Vidinsky B, Toporcer T, Mokry M, Mozes S, Longaver F, et al. Histological assessment of the effect of laser irradiation on skin wound healing in rats. Photomed Laser Surg 2006; 24(4): 480-8. [CrossRef]

23. Corallo C, Battisti E, Albanese A, Vannoni D, Leoncini R, Landi G, et al. Proteomics of human primary osteoarthritic chondrocytes exposed to extremely low-frequency electromagnetic fields (ELF EMFs) and to therapeutic application of musically modulated electromagnetic fields (TAMMEF). Electromagn Biol Med 20l4; 33(I): 3-10. [CrossRef] 
24. Tay AG, Farhadi J, Suetterlin R, Pierer G, Heberer M, Martin I. Cell yield, proliferation, and postexpansion differentiation capacity of human ear, nasal, and rib chondrocytes. Tissue Eng 2004; I0(5-6): 762-70. [CrossRef]

25. Pelttari K, Pippenger B, Mumme M, Feliciano S, Scotti C, Mainil-Varlet $P$, et al. Adult human neural crest-derived cells for articular cartilage repair. Sci Transl Med 20l4; 6(25I): 25Irall9. [CrossRef]

26. Candrian C, Vonwil D, Barbero A, Bonacina E, Miot S, Farhadi J, et al. Engineered cartilage generated by nasal chondrocytes is responsive to physical forces resembling joint loading. Arthritis Rheum 2008; 58(I): 197-208. [CrossRef]

27. Manni $\bigvee$, Lisi A, Rieti S, Serafino A, Ledda M, Giuliani L, et al. Low electromagnetic field $(50 \mathrm{~Hz})$ induces differentiation on primary human oral keratinocytes (HOK). Bioelectromagnetics 2004; 25(2): 118-26. [CrossRef]

28. Zhang M, LiX, Bai L, Uchida K, Bai W, Wu B, et al. Effects of low frequency electromagnetic field on proliferation of human epidermal stem cells: An in vitro study. Bioelectromagnetics 2013; 34(I): 74-80. [CrossRef]

29. Vincent TL, Hermansson MA, Hansen UN, Amis AA, Saklatvala J. Basic fibroblast growth factor mediates transduction of mechanical signals when articular cartilage is loaded. Arthritis Rheumatol 2004; 50(2): 526-33. [CrossRef]
30. Fitzsimmons RJ, Ryaby JT, Magee FP, Baylink DJ. IGF-II receptor number is increased in TE- 85 osteosarcoma cells by combined magnetic-fields. J Bone Miner Res 1995; I0(5): 812-9. [CrossRef]

31. De Mattei M, Pellati A, Pasello M, Ongaro A, Setti S, Massari L, et al. Effects of physical stimulation with electromagnetic field and insulin growth factor-I treatment on proteoglycan synthesis of bovine articular cartilage. Osteoarthritis Cartilage 2004; I2(I0): 793-800. [CrossRef]

32. Ciombor DM, Lester G, Aaron RK, Neame P, Caterson B. Low frequency EMF regulates chondrocyte differentiation and expression of matrix proteins. J Orthop Res 2002; 20(I): 40-50. [CrossRef]

33. Solek P, Majchrowicz L, Bloniarz D, Krotoszynska E, Koziorowski M. Pulsed or continuous electromagnetic field induce p53/p2l-mediated apoptotic signaling pathway in mouse spermatogenic cells in vitro and thus may affect male fertility. Toxicology 2017; 382: 84-92. [CrossRef]

34. Liu Y, Liu WB, Liu KJ, Ao L, Cao J, Zhong JL, et al. Extremely Low-Frequency Electromagnetic Fields Affect the miRNA-Mediated Regulation of Signaling Pathways in the GC-2 Cell Line. PLoS One 20I5; IO(I0): e0139949. [CrossRef]

35. Zhou J, Ming LG, Ge BF, Wang JQ, Zhu RQ, Wei Z, et al. Effects of $50 \mathrm{~Hz}$ sinusoidal electromagnetic fields of different intensities on proliferation, differentiation and mineralization potentials of rat osteoblasts. Bone 2011; 49(4): 753-61. [CrossRef] 